Jurnal Qua Teknika, Vol. 8 No. 1 Maret 2018

p-ISSN: 2088-2424; e-ISSN: 2527-3892

Fakultas Teknik Universitas Islam Balitar, Blitar

Http://qua.unisbablitar.ejournal.web.id; Email; quateknika@Gmail.com

Ikbal. 2018. Tegangan pemulihan pada kontak pemutus daya tegangan tinggi untuk proteksi terhadap gelombang.

Jurnal Qua Teknika, (2018), 8 (1) : 11-21

\title{
TEGANGAN PEMULIHAN PADA KONTAK PEMUTUS DAYA TEGANGAN TINGGI UNTUK PROTEKSI TERHADAP GELOMBANG BERJALAN
}

\author{
Ikbal \\ Program Studi Teknik Elektro Fakultas Teknik, Universitas Islam Balitar \\ Jl. Majapahit No. 4 Blitar Jawa Timur \\ Email : Quateknika@unisbablitar.ac.id
}

\begin{abstract}
ABSTRAK
In general we have known the frequent disruption of transmission lines is a natural disturbance, such as lightning disturbance to the transmission network due to transmission network through the air, long, high and spread in various open areas and operate in all kinds of conditions. Among the considerations taken in the transmission line transmission design is the location of the ground wire against the phase wire. Because the ground wire only, so a small percentage on the phase wire. And until now there are no scholars who show the use of lightning for life, have not got a way to prevent or exploit the energy caused by the lightning. Nevertheless, human science continues to thrive with technological advances. With one safety device, an air wire (Overhead Ground Wire) to protect the phase wires from the transmission line.
\end{abstract}

Keywords: high voltage, transmission, lightning, voltage protection, recovery voltage, wave protection

Pada umumnya kita telah mengetahui seringnya gangguan terhadap jaringan transmisi adalah gangguan alam, seperti gangguan kilat terhadap jaringan transmisi disebabkan jaringan transmisi yang melalui udara, panjang, tinggi dan tersebar diberbagai daerah terbuka serta beroperasi dalam segala macam kondisi. Diantara pertimbang-pertimbangan yang diambil dalam perancangan pemerisaian saluran transmisi adalah letak kawat tanah terhadap kawat fasa. Karena kawat tanah saja, sehingga persentase kecil saja pada kawat fasa. Sampai sekarang belum ada sarjana-sarjana yang menunjukan kegunaan kilat bagi kehidupan, belum mendapat jalan untuk mencegah atau memanfaatkan energi yang ditimbulkan oleh petir tersebut. Walaupun demikian ilmu pengetahuan menusia tetap berkembang dengan kemajuan teknologi. Dengan salah satu alat pengaman, kawat udara (Overhead Ground Wire) untuk melindungi kawat- kawat fasa dari jaringan transmisi.

Kata Kunci: tegangan tinggi, transmisi, petir, proteksi tegangan, tegangan pemulihan, proteksi gelombang

\section{METODE PENELITIAN}

Penelitian ini meliputi data primer dan data sekunder. Data primer diperoleh melalui proses pengukuran langsung terhadap alat yang dipakai untuk obyek penelitian di PT. PJB Unit Pembangkitan Brantas - PLTA Lodoyo, sedangkan data sekunder sebagai pelengkap analisis didapat dari studi kasus terhadap sistem yang sudah terekam dalam dokumen PT. PJB Unit Pembangkitan Brantas - PLTA Lodoyo. Data data yang diperoleh dari peralatan pemutus tegangan (circuit Breaker), data operasi transmisi dan distribusi, sistem pembangkitan di PLTA, dan data-data gangguan yang terjadi di gardu induk PLTA lodoyo. Pelaksanaan praktikum bertempat di PT. PJB UP BRANTAS PLTA LODOYO yang beralamatkan di dusun Serut desa Gogodeso, kecamatan Kanigoro, Kabupaten Blitar. Pelaksanaan praktik pada tanggal 3 April 2013 - 30 April 2017.

Penelitian ini bertujuan untuk memperoleh pemahaman yang jelas mengenai perhitungan pelindungan pada jaringan transmisi tegangan tinggi. Pengujian dilakukan di PT. PJB UP BRANTAS PLTA LODOYO. Sebelum pengujian dilaksanakan, dilakukan pengumpulan bahan terlebih dahulu. Setelah itu, dianalisis secara kualitatif dan kuantitatif agar data menjadi lebih mudah diinterpretasikan dan dipahami. Hal ini akan membuat informasi yang akan disampaikan menjadi lebih mudah. Pengolahan dan analisis secara deskriptif dan disajikan dalam bentuk tabel, gambar, dan grafik. Setelah pengumpulan data selesai, dilakukan pelaksanaan praktikum untuk Persoalan gelombang berjalan ini sangat sukar, sehingga harus diadakan banyak penyederhanaan supaya dapat dipergunakan untuk keperluan teknik pada saat ini gelombang berjalan telah diselidiki pada Kawat Tunggal, Kawat Majemuk, Kecepatan mejemuk dari gelombang berjalan. Bagian terbesar dari suatu mengenai gangguan pada system ialah teori gelombang berjalan, yaitu mengenai sumber gelombang, karakteristik serta keadaan pada titik peralihan dari transmisi. Pada gambar 3.1 dibawah ini memperlihatkan apabila suatu gelombang energi listrik merambat sepanjang kawat fasa dengan konstanta L dan C, maka 
Jurnal Qua Teknika, Vol. 8 No. 1 Maret 2018

p-ISSN: 2088-2424; e-ISSN: 2527-3892

Fakultas Teknik Universitas Islam Balitar, Blitar

Http://qua.unisbablitar.ejournal.web.id; Email; quateknika@Gmail.com

Ikbal. 2018. Tegangan pemulihan pada kontak pemutus daya tegangan tinggi untuk proteksi terhadap gelombang.

Jurnal Qua Teknika, (2018), 8 (1) : 11-21

gelombang tegangan dengan arus merambat dengan kecepatan yang sama. Kedua besaran ini dihubungkan oleh suatu factor proposional yaitu karakteristik fasa itu.

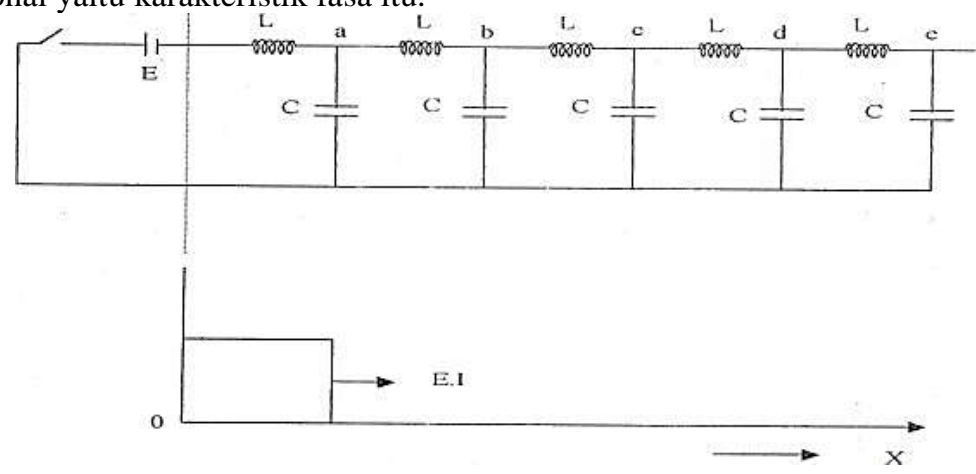

Gambar 3.1 Kawat Transmisi dengan batere

Bila gelombang tegangan $\mathrm{E}$ sampai pada titik a, maka arus yang bersamaan dari tegangan itu akan mengisi kapasitor $\mathrm{C}$ pada tegangan E. Muatan yang dibutuhkan untuk menaikan tegangan pada satu satuan panjang dama dengan CE. Bila kecepatan merambat gelombang itu $\mathrm{v} \mathrm{cm} / \mathrm{detik}$, maka jumlah muatan yang dibutuhkan untuk mengisi kawat sepanjang $\mathrm{v} \mathrm{cm}$ tiap detik sama dengan $\mathrm{C} \mathrm{E} \mathrm{v}$. Muatan ini diberikan oleh arus uniform yang mengalir pada kawat, dan memberikan muatan $\mathrm{C} E \mathrm{v}$ dalam satu detik dibutuhkan arus sebesar :

$\mathrm{I}=\mathrm{C} \mathrm{E} \mathrm{v}$

Bila gelombang itu merambat sejauh $\mathrm{x} \mathrm{cm}$, maka energi elektrostatik pada bagian ini $(\mathrm{x} \mathrm{cm})$ ialah :

$\mathrm{Wc}=1 / 2 \mathrm{C} \times \mathrm{E}^{2}$

Bila L sama dengan induktansi kawat per $\mathrm{cm}$, maka dalam waktu yang sama, energi elektromagnetik pada kawat sepanjang $\mathrm{x}$ itu :

$\mathrm{W}_{\mathrm{L}}=1 / 2 \mathrm{~L} \times \mathrm{I}^{2}$

(3.3)

Dimana :

$\mathrm{Wc}=$ Energi elektrostatik

$\mathrm{W}_{\mathrm{L}}=$ Energi elektromagnetik

$\mathrm{C}=$ Kapasitor

$\mathrm{L} \quad=$ Induktansi

$\mathrm{E} \quad=$ Tegangan batere

I = Arus yang mengantar pada kawat fasa

Satu-satunya sumber energi disini batere. Bila dibutuhkan waktu t entuk merambat sepanjang $\mathrm{x} \mathrm{cm}$,

$\mathrm{v}=\mathrm{x} / \mathrm{t}$

Energi yang diberikan oleh batere

$$
\begin{aligned}
& \mathrm{W}_{\mathrm{e}}=\mathrm{EIt} \\
& \mathrm{W}_{\mathrm{e}}=\mathrm{Wc}+\mathrm{W}_{\mathrm{L}} \\
& \text { Jadi : } \mathrm{E} \text { I } t=1 / 2 C \times E^{2}+1 / 2 L \times I^{2} \\
& E I=1 / 2 C v E^{2}+1 / 2 L v I^{2} \\
& \mathrm{v}=\frac{2}{\mathrm{CE} / \mathrm{I}+\mathrm{LI} / \mathrm{E}} \\
& \text { Dari, I = C E v } \\
& \frac{\mathrm{E}}{\mathrm{I}}=\frac{\mathrm{I}}{\mathrm{CV}} \\
& \mathrm{v}=\frac{2}{\mathrm{I} / \mathrm{v}+\mathrm{LC} \mathrm{v}} \\
& \mathrm{v}=\mathrm{I} \quad \text { atau } \mathrm{v}= \pm \sqrt{ } \quad 1 \\
& \text { LC LC }
\end{aligned}
$$

Kedua harga $+\mathrm{v}$ dan $-\mathrm{v}$ berlaku, yaitu 
Jurnal Qua Teknika, Vol. 8 No. 1 Maret 2018

p-ISSN: 2088-2424; e-ISSN: 2527-3892

Fakultas Teknik Universitas Islam Balitar, Blitar

Http://qua.unisbablitar.ejournal.web.id; Email; quateknika@Gmail.com

Ikbal. 2018. Tegangan pemulihan pada kontak pemutus daya tegangan tinggi untuk proteksi terhadap gelombang.

Jurnal Qua Teknika, (2018), 8 (1) : 11-21

$\mathrm{v}$ positif = gelombang maju

$\mathrm{v}$ negative $=$ gelombang mundur

Untuk kawat hantaran udara jari-jari $\mathrm{r}$ dan tinggi h diatas tanah, mempunyai harga induktansi dan kapasitas masing-masing:

$\mathrm{L}=\left(\begin{array}{l}\frac{1}{2}+\frac{2 \mathrm{~h}}{\mathrm{r}}\end{array}\right) 10^{-9}$ Henry $/ \mathrm{cm}$

Faktor $1 / 2$ yang ditimbulkan pada induktansi persamaan (3.7), disebabkan oleh adanya fluks didalam kawat (Internal Flux(, dengan pemisahaan distribusi arus merata. Tetapi pada gelombang berjalan, "Transient Skin Effect" sangat besar, sehingga arus berkumpul pada permukaan kawat. Dengan demikian internal fluks lingkup sangat kecil dan dapat diabaikan, menjadi :

$\mathrm{L}=2 \operatorname{In} \frac{2 \mathrm{~h}}{2} 10^{-9}$ Henry $/ \mathrm{cm}$

Dan kapasintasinya $: \mathrm{C}=10-11 \quad$ Farad $/ \mathrm{cm}$

$$
18 \operatorname{In} \frac{2 \mathrm{~h}}{\mathrm{r}}
$$

jadi dengan mensubtitusi persamaan (3.8) dan (3.9) kepersamaan (3.6) akan diperoleh kecepatan gelombang berjalan sebesar :

$\mathrm{v}=3.10^{10} \mathrm{~cm} /$ detik

Dari persamaan (3.10) terlihat bahwa kecepatan gelombang berjalan pada kawat hantaran udara adalah sama dengan kecepatan cahaya dalam hampa udara. Sedangkan untuk kabel konduktor padat dengan jari-jari (r) dan isolasi pembungkus berjari-jari $(\mathrm{R})$ serta permitivitas $(\varepsilon)$ :

$\mathrm{L}=2\left(\mathrm{In} \frac{\mathrm{R}}{\mathrm{r}}+\frac{1}{2}-\frac{\mathrm{r}^{2}}{3 \mathrm{R}^{2}}+\frac{\mathrm{r}^{4}}{12 \mathrm{R}^{4}}+\frac{\mathrm{r}^{6}}{60 \mathrm{R}^{6}}\right) 10^{-9}$

Tetapi fluks lingkup dalam dapat diabaikan, karena $r$ jauh lebih kecil dari $\mathrm{R}$ maka faktor dapat diabaikan, maka akan didapat :

$\frac{r^{2}}{3 R^{2}}$ dan seterusnya $\mathrm{R}$

$\mathrm{L}=2.10-9$ In $-($ Henry/cm)

$$
\mathrm{C}=\frac{\varepsilon \cdot 10^{-11}}{18 \operatorname{In} \frac{\mathrm{R}}{\mathrm{r}}}(\text { Farad } / \mathrm{cm})
$$

Jadi kecepatan merambat pada kabel adalah :

$$
=\frac{3.10}{\sqrt{\varepsilon}} \mathrm{cm} / \text { detik }
$$

Untuk kabel-kabel yang tersedia umumnya $\varepsilon-2.5-4$ jadi kecepatan merambat dalam kabel kira-kira $1 / 2$ sampai $2 / 3$ kecepatan cahaya. 
Jurnal Qua Teknika, Vol. 8 No. 1 Maret 2018

p-ISSN: 2088-2424; e-ISSN: 2527-3892

Fakultas Teknik Universitas Islam Balitar, Blitar

Http://qua.unisbablitar.ejournal.web.id; Email; quateknika@ Gmail.com

Ikbal. 2018. Tegangan pemulihan pada kontak pemutus daya tegangan tinggi untuk proteksi terhadap gelombang.

Jurnal Qua Teknika, (2018), 8 (1) : 11-21

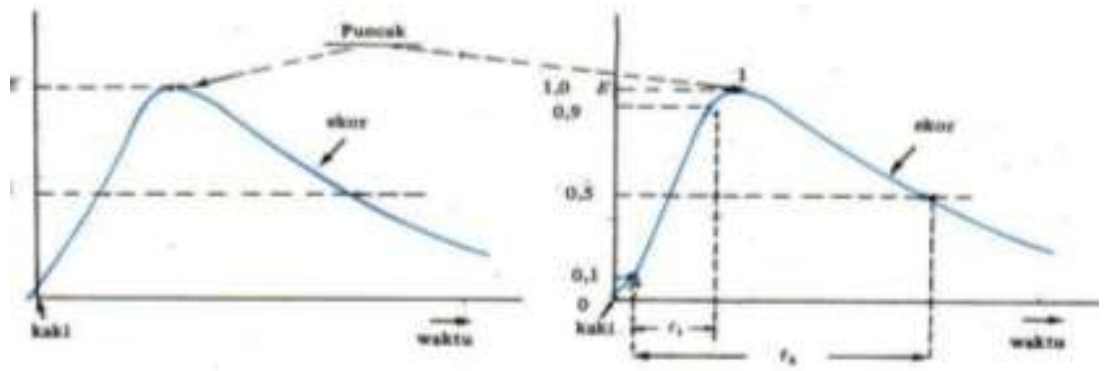

Gambar 3.2 : Spesifikasi gelombang

Spesifikasi dari suatu gelombang berjalan :

a. Tegangan puncak (Crest) dari gelombang, E (KV), yaitu amplitude maksimun dari gelombang.

b. Muka gelombang (Front), $\mathrm{t}_{1}$ (mikrodetik), yaitu waktu dari permulaan sampai puncak. Dalam praktek ini diambil dari $10 \%$ E samapi $90 \% \mathrm{E}$, lhat gambar 3.2b.

c. Ekor gelombang (Tail) yaitu bagian kebelakang puncak. Panjang gelombang (Lengght) $\mathrm{t}_{2}$ (mikrodetik) yaitu waktu dari permulaan sampai titik $50 \%$ E pada tail.

d. Polaritas (Polarity) yaitu polaritas dari gelombang positif atau negative. Suatu gelombang berjalan (surja) dinyatakan sebagai berikut :

$$
\mathrm{E}, \mathrm{t}_{1} \times \mathrm{t}_{2}
$$

Jadi suatu gelombang dengan polaritas positif, crest $=1000 \mathrm{KV}$, front 3 mikrodetik, dan panjang 21 mikrodetrikdinyatakan sebagai : + 1000, 3 x 21 .

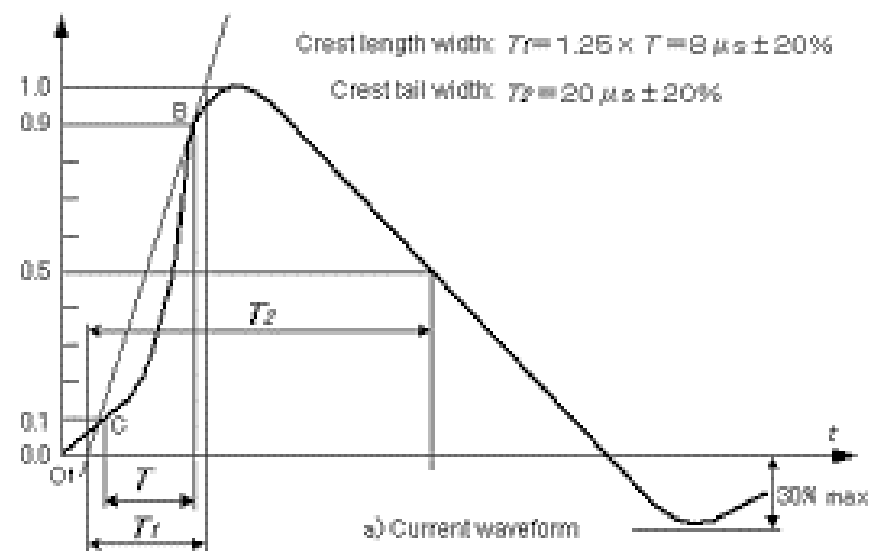

Gambar. 3.3 Gelombang Kombinasi

Gelombang persegi yang sangat panjang sering digunakan dalam mengitung gelombang berjalan terhadap keamanan sistem, kerena gelombang seperti ini paling berbahaya bagi peralatan. Kecuraman gelombang akan menyebabkan gradient yang maksimun sedangkan ekor yang panjang menyebabkan osilasi maksimun pada belitan kumparan mesin.

Gangguan kilat tipikal merupakan bentuk yang paling mirip dengan bentuk gelombang surja petir(Lighting surge) yang dilihat pada osiloskop. Bentuk gelombang ini tergantung dari a dan $b$, sebaliknya bila spesifikasi gelombang diberi a, b, dan E dapat dicari.

Bila $\mathrm{E}, \mathrm{a}, \mathrm{b}$, diketahui dapat ditentukan puncak, muka, dan panjang gelombang itu. 


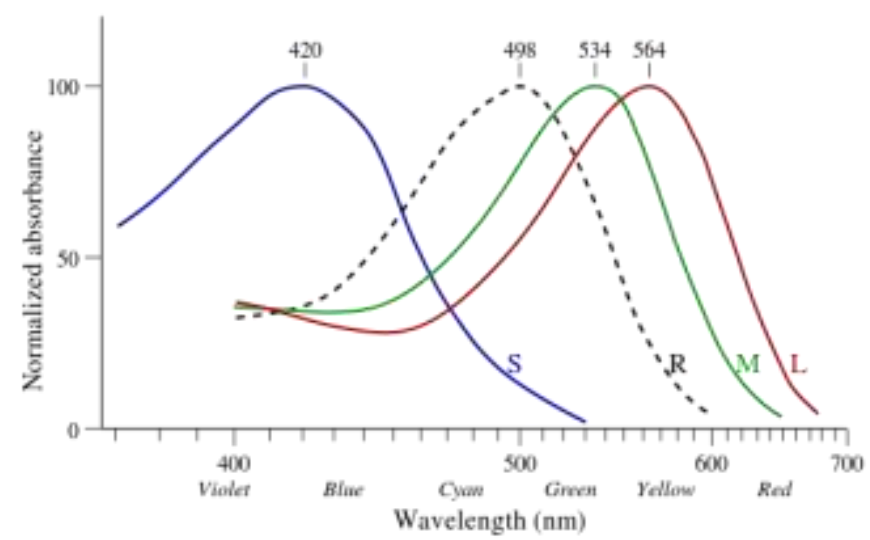

Gambar. 3.4 Grafik Panjang Gelombang

Contoh penggunaan grafik untuk menetukan konstanta-konstanta a, b, dan E, untuk gelombang + $1000,3 \times 21: \mathrm{t}_{2} / \mathrm{t}_{1}=7$. Dari lengkungan $\mathrm{t}_{2} / \mathrm{t}_{1}$ didapat $\mathrm{b} / \mathrm{a}=28.5$, Selanjutnya dari $\mathrm{b} / \mathrm{a}$ ini didapat $\mathrm{t}_{1}=0,122 / 3$ $=0,28$

Jadi : $\mathrm{a}=0,122 / \mathrm{t}_{1}=0,122 / 3=0,041$

$\mathrm{b}=28,5 \mathrm{a}=28,5 \times 0,041=1,15$

$\mathrm{E}=\mathrm{E}_{1} / 0,825=1000 / 0,825=1175$

Gelombang tersebut adalah $\mathrm{E}=1175\left(\mathrm{e}^{-0,041}-\mathrm{e}^{-1,151}\right)$

\section{HASIL DAN PEMBAHASAN}

\section{Kawat Tanah Udara (Overhead Ground Wire)}

Kawat tanah udara adalah kawat konduktor, st atau AsCR ditempatkan diatas kawat-kawat fasa. Mulanya kawat ini dimaksudkan sebagai proteksi terhadap induced stroke (induksi yang disebabkan oleh sambaran kilat disekitar kawat transmisi, jadi sambaran tidak langsung). Akan tetapi kemudian ternyata dari praktek maupun teori sebagi utama yang menimbulkan gangguan adalah sambaran langsung atau direct stroke.

\section{Sambaran Tak Langsung (Induced Stroke)}

Ketika arus listrik melalui awan jatuh kebumi, arus listrik tersebut menginduksi ditanah terhadap pengkutuban yang berlawanan dengn awan itu (Gambar.4.1). Bentuk kawasan awan tersebut terhadap menyebar dan menutup sebagian permukaan tanah, permukaan tanah yang tertutup itu lebih besar dari pada permukaan awan itu sendiri. Dasar bagian bawah dari pada awan itu biasanya bersifat negatif, jadi induksi arus listrik di bumi biasanya bersifat positif. Jika kawat transmisi merupakan suatu garis pemisah antara permukaan awan dan tanah, arus listrik akan kelihatan di permukaan garis konduktor dan kawat tanah.

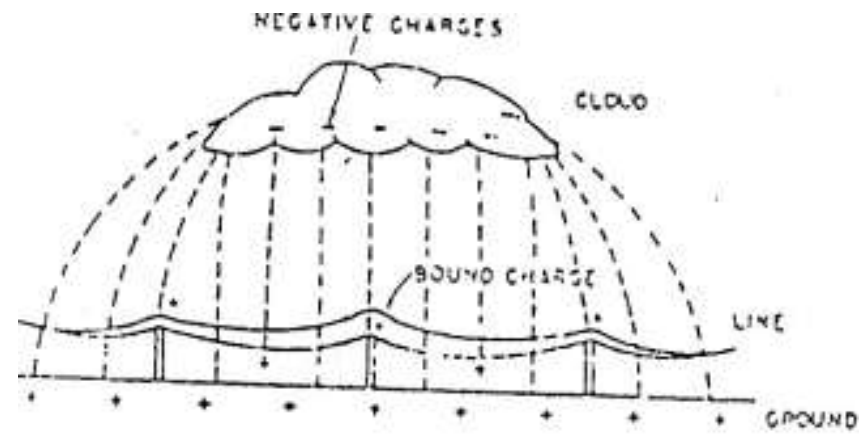

Gambar 4.1. Daerah awan dan batasan dari anah dan jaringan transmisi 
Jurnal Qua Teknika, Vol. 8 No. 1 Maret 2018

p-ISSN: 2088-2424; e-ISSN: 2527-3892

Fakultas Teknik Universitas Islam Balitar, Blitar

Http://qua.unisbablitar.ejournal.web.id; Email; quateknika@Gmail.com

Ikbal. 2018. Tegangan pemulihan pada kontak pemutus daya tegangan tinggi untuk proteksi terhadap gelombang.

Jurnal Qua Teknika, (2018), 8 (1) : 11-21

Kumpulan arus listrik pada garis konduktor disebabkan oleh kebocoran sekliling isolator dan perputaran dari pada konudktor diluar pengaruh awan. Arus listrik lebih mudah mengumpul diatas kawat tanah dengan perpindahan tegak lurus terhadap menata dari tanah.

Jika sambaran yang berasal dari awan mengenai tanah dekat garis pemisah, daerah awan akan runtuh pada waktu tertentu dan lompatan arus listrik digaris konduktor dan bebas bergerak berlawanan arah, membentuyk putaran gelombang mungkin berakhir membentuk dataran aliran arus (Gambar 4.2).

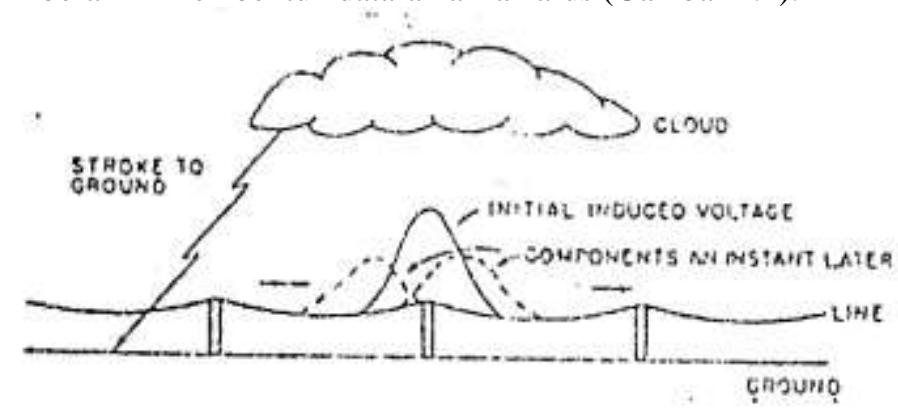

Gambar. 4.2. Induksi tegangan di jaringan transmisi dengan keruntuhan daerah awan.

Arus listrik pada bawah kawat tanah berbatasan dengan menara-menara dan pada garis konduktor bergerak sangat cepat dan menghilangkan secara brangsur-angsur di corona serta kehilangan muatan. Tegangan listrik muncul digaris abtas tergantung kepada perbandingan (ukuran) dari pada keruntuhan daerah awan dan kapasitas kemampuan ruangan antara jaringan dan tanah, kalau circuit tanpa kawat-kawat tanah udara, dan kalau terjadi keruntuhan daerah awan pada waktu nol, tegangan listrik di konduktor akan sebanding dengan peningkatan potensial gradien dari pengadaan pembesaran ketinggian awan dari pada kawat tanah udara diatas permukaan tanah menambah kekautan penghantar dibumi, dan dengan peningkatan awan yang banyak mendatangkan lingkaran cahaya, kapasitas selanjutnya bertambah sebab efektif diameter tanah bertambah dengan lingkaran cahaya.

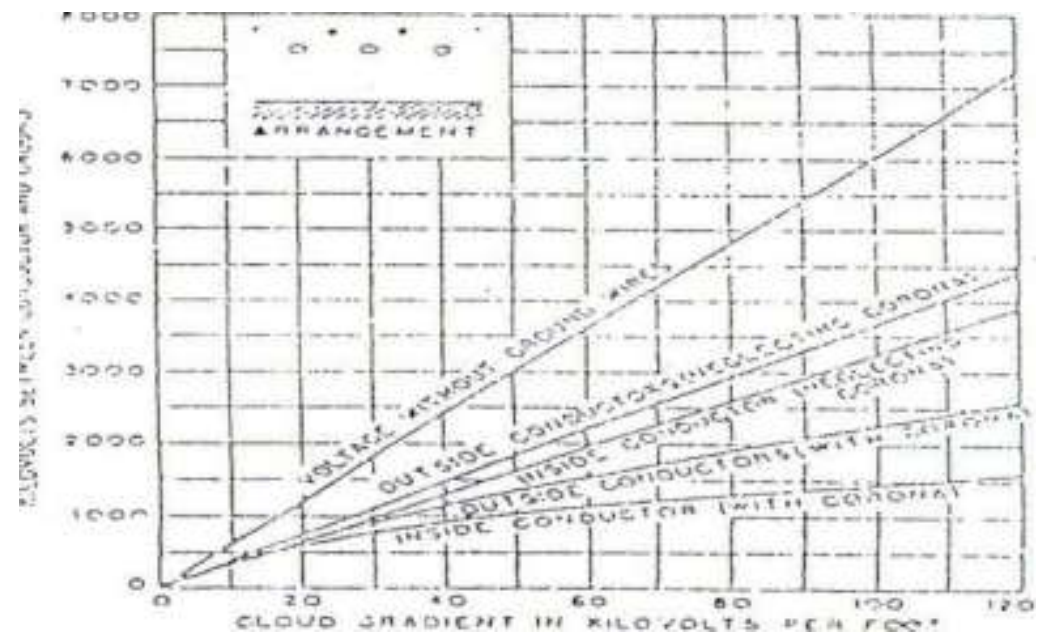

Gambar.4.3. Induksi potensial diantara konduktor dan tanah dekat stroke dari awan ke tanah.

Gambar 4.3. menunjukkan induksi tegangan listrik antara penghantar dan tanah untuk perbedaan gradien awan dan tanpa kawat tanah, untuk jaringan diatas ketinggian tanah dan jarak antara konduktor dari pada ratarata jaringan tegangan tinggi.

Perbandingan perhitungan-perhitungan tegangan dari konduktor dengan proteksi kawat tanah dengan perbandingan tegangan yang ada pada konduktor tanpa proteksi kawat tanah.

Gambar 4.4. Menghitung harga dari puncak tegangan induksi pada jaringan transmisi dekat stroke, menggambarkan dari arus stroke, jarak saluran dari arus stroke, jarak saluran darai ketinggian konduktor. 
Jurnal Qua Teknika, Vol. 8 No. 1 Maret 2018

p-ISSN: 2088-2424; e-ISSN: 2527-3892

Fakultas Teknik Universitas Islam Balitar, Blitar

Http://qua.unisbablitar.ejournal.web.id; Email; quateknika@Gmail.com

Ikbal. 2018. Tegangan pemulihan pada kontak pemutus daya tegangan tinggi untuk proteksi terhadap gelombang.

Jurnal Qua Teknika, (2018), 8 (1) : 11-21

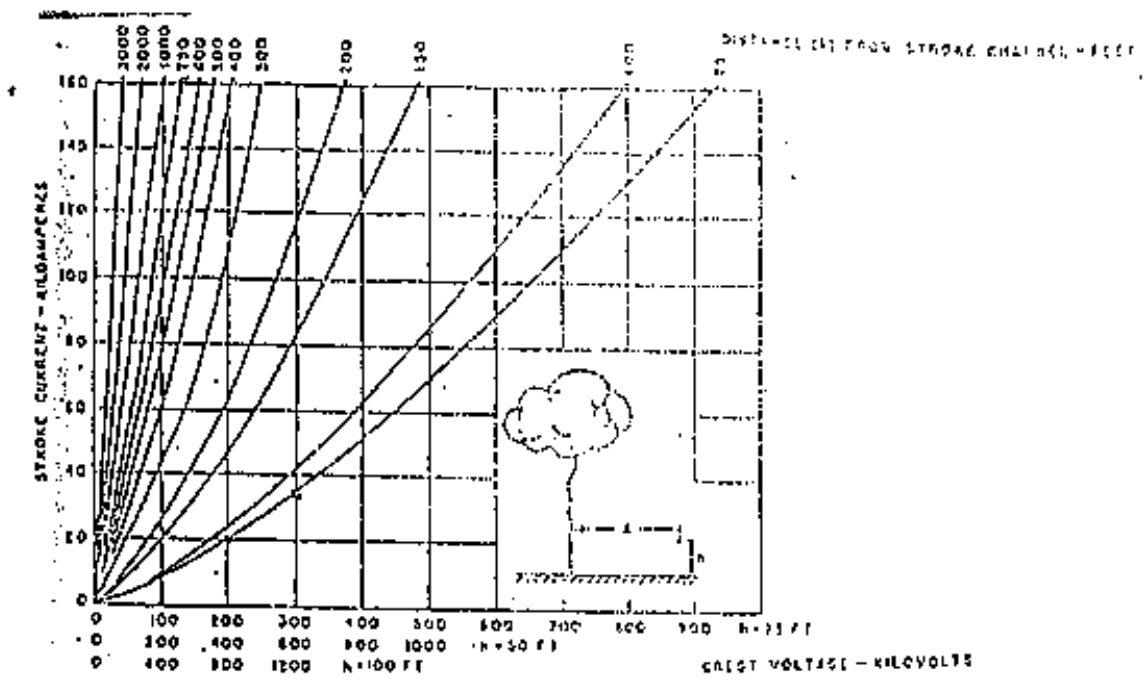

Tegangan menghasilkan keseimbangan ketinggian dari konduktor jaringan transmisi puncak dari arus listrik kepada sambaran ke tanah dan ajrak dari saluran sambaran. Gambar 4.4. memberikan perhitungan tertinggi dari pada penginduksian arus listrik yang bergelombang pada sebuah konduktor yang tidak dilindungi oleh kawat tanah udara dan berfungsi sebagai sambaran arus, jarak dari aliran samabran dan ketinggian dari pada penghantar. Perhitungan pada kurva seperti terlihat pada Gambar 4.4. dapat diketahui kecepatan arus listrik bolak-balik untuk perbedaan arus listrik pada suatu tempat sebagai berikut : 0-50.000 ampere 120 kaki per us; 50.000-10.000 amperes, 400 kaki per us. Memperlihatkan keadaan yang kurang baik dari pada gambar arus yang tinggi, susunan transmisi yang tinggi dan sambaran kepermukaan tanah dekat susunan transmisi, puncak tegangan yang pertama pada ukuran $1000 \mathrm{KV}$ mungkin dapat menginduksi dibawah konduktor. Pengurangan isi dapat terlihat jika kawat-kawat tanah udara yang melalui udara dapat dikurangi.

\section{Sambaran Langsung Pada Menara}

Untuk sambaran langsung, kawat tanah melindungi (shileding) kawat fasa, dan untuk memperoleh perlindungan yang baik kedudukan kawat tanah harus memenuhi beberapa persyaratan yang penting:

a. Kawat tanah harus cukup tinggi diatas kawat fasa dan diatur sedemikian rupa agar dapat mencegah sambaran pada kawat-kawat fasa.

b. Pada tengah gawang kawat tanah harus mempunyai jarak yang cukup di atas kawat fasa untuk mencegah terjadinya loncatan sebagian pada waktu yang diperlukan untuk gelombang pantulan negatif dari menara kembali ke tengah gawang dan ini akan mengurangi tegangan pada tengah gawan.

c. Tahanan kaki menara harus cukup rendah untuk membatasi tegangan pada isolator agar tidak terjadi loncatan api pada isolator.

d. Bila dipakai untuk proteksi terhadap gardu induk, kawat tanah harus cukup panang sehingga surja yang masuk dapat diredam sampai harga yang tidak berbahaya sewaktu mencapai gardu induk.

Sambaran langsung merupakan sebab utama dari gangguan yang disebabkan oleh kilat. Bila sambaran mengenai menara transmisi, arus yang besar sekali mengalir ke tanah dan sepasang gelombang berjalan merambat pada kawat tanah.

Gambar 4.5. menunjukkan sambaran kilat dengan impedansi surja z ke menara, pada keadaan ideal. 
Jurnal Qua Teknika, Vol. 8 No. 1 Maret 2018

p-ISSN: 2088-2424; e-ISSN: 2527-3892

Fakultas Teknik Universitas Islam Balitar, Blitar

Http://qua.unisbablitar.ejournal.web.id; Email; quateknika@Gmail.com

Ikbal. 2018. Tegangan pemulihan pada kontak pemutus daya tegangan tinggi untuk proteksi terhadap gelombang.

Jurnal Qua Teknika, (2018), 8 (1) : 11-21

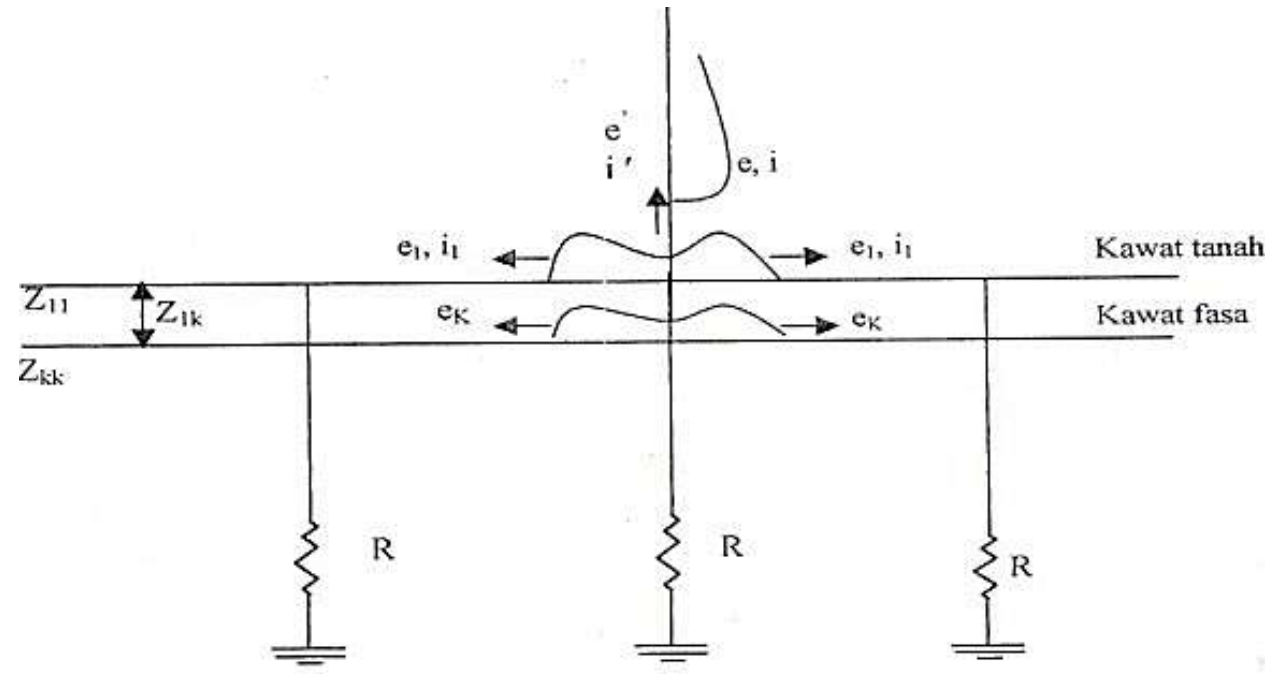

Gelombang $e_{1}$ merambat pada kawat tanah, dan gelombang induksi $e_{k}$ merambat pada kawat fasa.

Misalkan :

$\mathrm{Z}=$ impedansi surja dari kilat $(\mathrm{ohm})$

$\mathrm{Z}_{11}=$ impedansi surja sendiri dari kawat equivalen

$Z_{\mathrm{kk}}=$ impendansi suya sendiri

$\mathrm{Z}_{\mathrm{k}}=$ impedansi surja bersama antara kawat tanah equivalen dengan kawat fasa $\mathrm{k}$

$\mathrm{e} \quad=\quad$ gelombang pantulan sambaran kilat (volt)

è $\quad=\quad$ gelombang pantulan pada kanal sambaran kilat

$\mathrm{e}_{1} \quad=\quad$ gelombang datang pada kawat tanah

$\mathrm{e}_{\mathrm{k}} \quad=\quad$ gelombang datang pada kawat fasa $\mathrm{k}$

$\mathrm{R}=$ tahanan kaki menara $(\mathrm{Ohm})$

$1=$ arus menara $(\mathrm{A})$

Karena tidak ada arus yang mengalir dari menara ke kawat fasa,

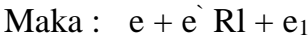

$i+i=2 i_{1}+1$

dimana, $\mathrm{I}=\mathrm{e} / \mathrm{Z} ; \mathrm{i}=-\mathrm{e} / \mathrm{Z}: \mathrm{i}_{1}=\mathrm{e}_{1} / \mathrm{Z}_{11}$

Ketika gelombang $\mathrm{e}_{1}$ dan $\mathrm{e}_{\mathrm{k}}$ mencapai menara berikutnya, direfleksikan dan relaksikan. Sekarang ditinjau suatu sistem $\mathrm{n}$ kondukor dengan $\mathrm{m}$ kawat tanah pada suatu menara yang ditanahkan melalui tahanan $\mathrm{R}$.

\section{Perlindungan Gardu Induk}

Perlindungan terhadap sambaran langsung ialah dengan kawat tanah. Bila perlindungan ini sempurna, maka yang perlu diperhatikan adalah gelombang yang datang dari kawat transmisi. Bila kawat-kawat fasa cukup terlindung dari sambaran langsung, maka sumber gelombang berjalan biasanya adalah lompatan api dari isolator, umumnya tegangan ini lebih tinggi dari tingkat isolari dasar (ITD) dari peralatan gardu, tegangan lebih ini harus dilakukan ke tanya oleh arrester atau alat-alat perlindungan lainnya. Sepanjang perambatan pada kawat transmisi, gelombang mengalami redaman dan distorsi yang disebabkan oleh korona, pengaruh kulit, resitivitas tanah, dan gendengan. Selain itu, bentuknya juga dapat berubah karena pantulan ketika mencapai gardu.

\section{Akibat Pelindung Kawat Tanah}

Sebagai akibat dari mengalirnya energi sambaran ke dalam tanah, maka tegangan lebih yang timbul pada isolator saluran akan dapat dibatasi, dengan demikian penembusan pada isolator dapat dibatasi. Untuk memperoleh hasil yang unik maka penempatan kawat tanah haruslah memenuhi syarat, antara lain :

a. Kawat tanah harus cukup tinggi di atas fasa dan diatur sedemikian rupa agar dapat mencegah sambaran langsung pada kawat-kawat fasa.

b. Pada tengah gawang kawat tanah harus mempunyai kawat fasa untuk mencegah terjadinya loncatan sebagian 
Jurnal Qua Teknika, Vol. 8 No. 1 Maret 2018

p-ISSN: 2088-2424; e-ISSN: 2527-3892

Fakultas Teknik Universitas Islam Balitar, Blitar

Http://qua.unisbablitar.ejournal.web.id; Email; quateknika@Gmail.com

Ikbal. 2018. Tegangan pemulihan pada kontak pemutus daya tegangan tinggi untuk proteksi terhadap gelombang.

Jurnal Qua Teknika, (2018), 8 (1) : 11-21

c. Tahanan kaki menara harus cukup rendah. Tahanan kaki menara harus cukup rendah.

\section{Kegagalan Pelindung}

Mulai tahun 1920-an telah banyak teori-teori, percobaan-percobaan dan pengalaman-pengalaman dikemukakan para penyelidik mengenai fungsi kawat tanah untuk melindungi kawat fasa pada saluran transmisi. Pada tahun 1960 Provoost mengemukakan suatu resume yang sangat baik mengenai peranan kawat tanah. Berdasarkan teori itu Provoost menarik kesimpulan bahwa :

a. Untuik sudut pelindung $\theta \leq 18^{0}$ perisaian kawat transmisi itu baik

b. Untuk sudut pelindung $18^{0} \leq \theta<30^{\circ}$ kurang baik

c. Untuk sudut pelindung $\theta 30^{\circ}$ jelek

Kemudian konstenko, Poloroy dan Rosenfeld dalam tahun 1961 mengemukakan karangan yang lebih menari lagi. Mereka menunjukkan bahwa jumlah gangguan kilat karena kegagalan pelindung adalah sebagai fungsi dari sudut perisaian $\theta$ dan tinggi menara $\mathrm{h}_{\mathrm{t}}$ seperti terlihat dari relasi empiris persamaan :

$\log \varphi=\frac{\theta \sqrt{h_{1}}}{90}-4$

Dimana :

$\varphi=$ Hasil bagi dari jumlah kilat yang menenai kawat fasa dan jumlah kilat yang mengenai saluran transmisi.

$\theta=\quad$ Sudut pelindung pada menara, derajat

$\mathrm{h}_{\mathrm{t}}=\quad$ tinggi kawat tanah pada menara, meter

Jadi jumlah gangguan karena kegagalan pelindung, $\mathrm{N}_{\mathrm{SF}}=\varphi \mathrm{N}_{\mathrm{L}} \eta$

\section{Perhitungan Menentukan Sudut Perlindungan Pada Jaringan Transmisi Tegangan Tinggi}

Besarnya sudut perlindungan mempunyai hubungan-hubungan dengan tinggi menara, dimana semakin tinggi menara transmisi semakin tinggi kemungkinan kegagalan perlindungan.

Untuk melindungi (mengurangi) kegagalan perlindungan ini, haruslah dipilih sudut perlindungan yang kecil. Rumus yang dapat dipakai dalam menghitung sudut perlindungan seperti persamaan : $\theta=\operatorname{arc} \tan \frac{x}{h}$

Dimana $: \mathrm{h}=$ jarak antara kawat tanah dengan garis horizontal yang menghubungkan kawat fasa.

$\mathrm{x}=$ selisih antara panjang cross arm kawat tanah dengan kawat fasa

$\theta \quad=$ sudut perlindungan

a. Perhitungan sudut pelindung antara kawat tanah dengan kawat fasa $\mathrm{R}$

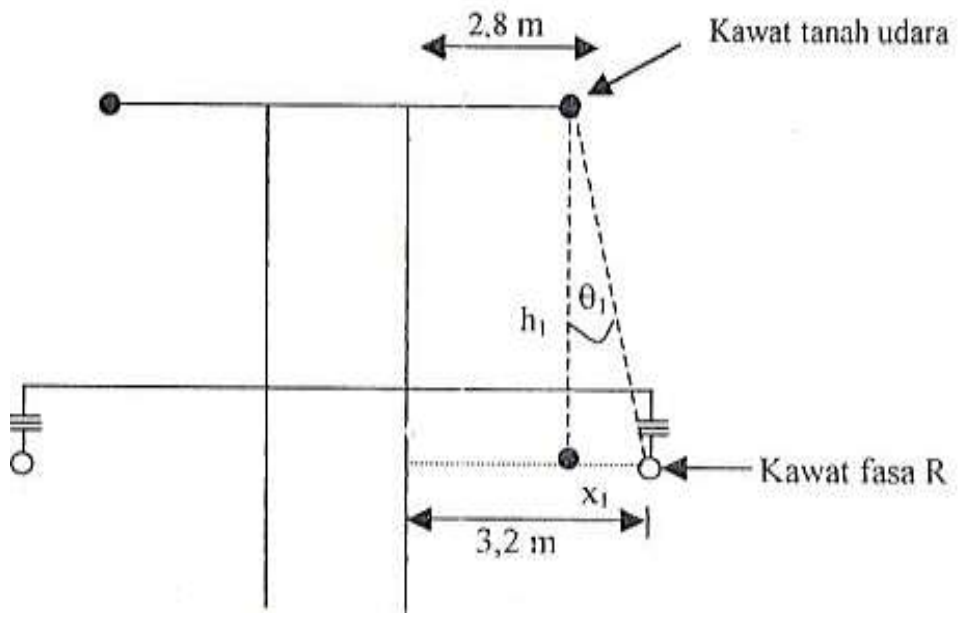

$$
\begin{aligned}
& \mathrm{x}_{1}=3,2-2,8=0,4 \mathrm{~m} \\
& \mathrm{~h}_{1}=5,22 \mathrm{~m} \\
& \theta_{1}=\arctan \frac{x}{h}
\end{aligned}
$$


Jurnal Qua Teknika, Vol. 8 No. 1 Maret 2018

p-ISSN: 2088-2424; e-ISSN: 2527-3892

Fakultas Teknik Universitas Islam Balitar, Blitar

Http://qua.unisbablitar.ejournal.web.id; Email; quateknika@Gmail.com

Ikbal. 2018. Tegangan pemulihan pada kontak pemutus daya tegangan tinggi untuk proteksi terhadap gelombang.

Jurnal Qua Teknika, (2018), 8 (1) : 11-21
$\theta_{1}=\arctan \frac{0,4}{5,22}$
$\theta_{1} \quad=4,38^{0}$

b. Perhitungan sudut pelindung antara kawat tanah dengan kawat fasa $\mathrm{S}$

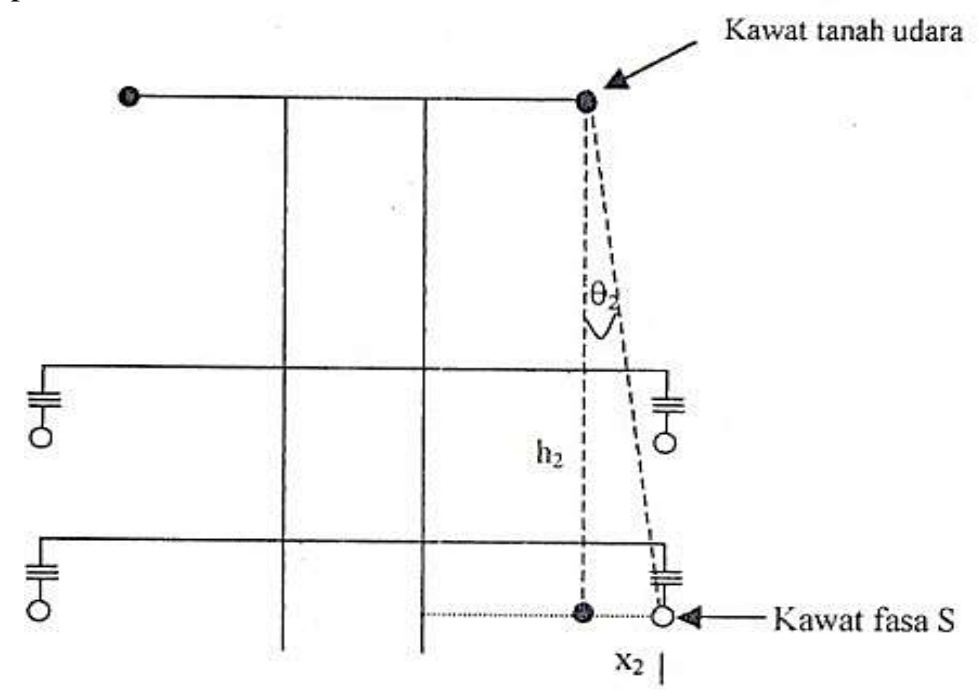

$$
\begin{aligned}
& \mathrm{x}_{1}=\mathrm{x}_{2}=0,4 \mathrm{~m} \\
& \mathrm{~h}_{2}=5,22+4,38=9,6 \mathrm{~m} \\
& \theta_{2}=\arctan \frac{x 2}{h 2} \\
& \theta_{2}=\arctan \frac{0,4}{9,6} \\
& \theta_{2}=2,39^{0}
\end{aligned}
$$

c. Perhitungan sudut pelindung antara kawat tanah dengan kawat fasa $\mathrm{T}$

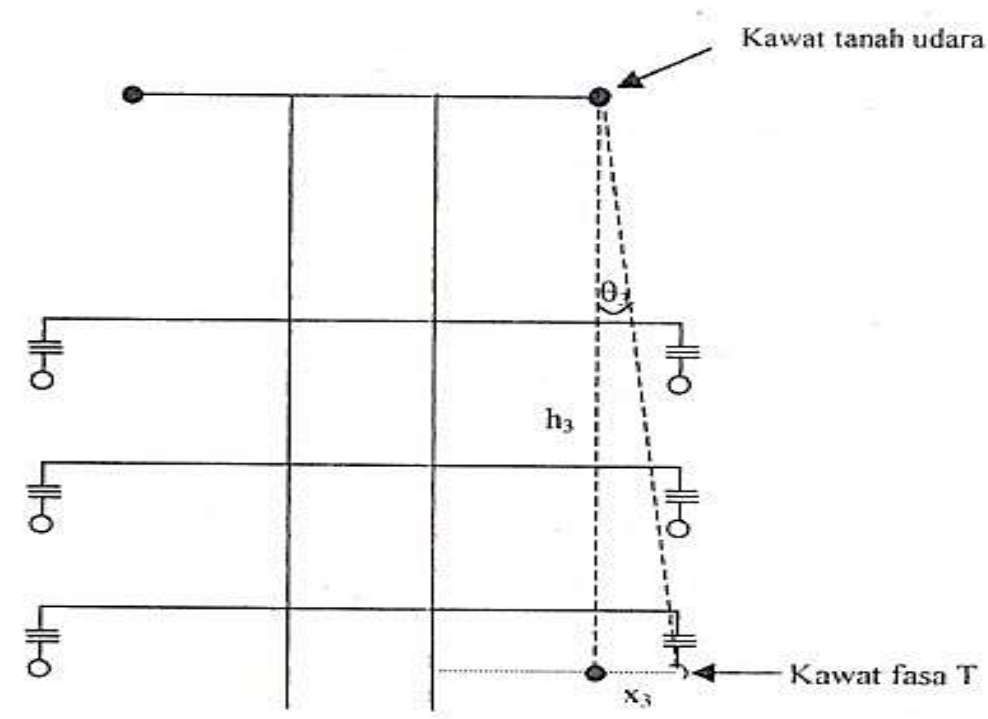

$\mathrm{x}_{1}=\mathrm{x}_{2}=\mathrm{x}_{3}=0,4 \mathrm{~m}$

$\mathrm{h}_{3} \quad=5,22+4,38=13,98 \mathrm{~m}$ 


$$
\begin{aligned}
\theta_{3} & =\arctan \frac{x 3}{h 3} \\
\theta_{3} & =\arctan \frac{0,4}{13,98} \\
\theta_{3} & =1,63^{0}
\end{aligned}
$$

\section{SIMPULAN}

Berdasarkan hasil dari penelitian ini, maka dapat ditarik kesimpulan sebagai berikut :

1. Seringnya gangguan terhadap jaringan transmisi adalah gangguan alam, seperti seringnya gangguan petir terhadap jaringan transmisi yang disebabkan bangunan jaringan transmisi panjang dan terbesar diberbagai daerah serta dalam segala macam kondisi udara.

2. Pada pembangunan jaringan transmisi yang sangat perlu diperhatikan adalah perancangan proteksi saluran transmisi terhadap letak kawat fasa

3. Konfigurasi kawat transmisi ini harus mendapat perhatian yang lebih besar dan serius.

4. Sudut pelindung kawat tanah sesuai dengan contoh perhitungan diperoleh untuk :

a. Nilai dari sudut pelindung antara kawat tanah dengan kawat fasa $\mathrm{R}$ adalah $\theta_{1}=4,38^{0}$

b. Nilai dari sudut pelindung antara kawat tanah dengan kawat fasa $\mathrm{S}$ adalah $\theta_{2}=2,39^{0}$

c. Nilai dari sudut pelindung antara kawat tanah dengan kawat fasa $\mathrm{T}$ adalah $\theta_{3}=1,63^{0}$ Jadi untu sudut pelindung $\theta<18^{0}$ pelindung kawat transmisi itu baik

\section{DAFTAR PUSTAKA}

Abdul M. Mousa, 1976, Shielding of High Voltage And Extra High Voltage Substation, IEEE Transaction on Power Apparatus and System; Vol. PAS-95.

A. Aris Munandar DR., 1978, Teknik Tegangan Tinggi, PT. Pradaya Paramita, Jakarta.

A. Aris Munandar DR., S. Kuwahara DR., 1975, Teknik Tenaga Listrik, Jilid II Saluran Transmisi, PT. Pradaya Paramita, Jakarta.

Hutauruk T. S., 1976. Pengetanahan Netral Sistem-sistem Tegangan Tinggi, Departemen Elektro Teknik Fakultas Teknologi Industri, ITB.

Hutauruk T. S., 1987. Pengetanahan Netral Sistem Tenaga dan Pengetanahan Peralatan, Institut Teknologi Bandung dan Univeristas Tri Sakti.

Hutauruk T. S., 1985. Transmisi Daya Elektrik, Institut Teknologi Bandung dan Univeristas Tri Sakti.

Hutauruk T. S., 1976. Gelombang Berjalan Pada Sistem Transmisi dan Proteksi dan Perlatan Pada Surja, Institut Teknologi Bandung. 